
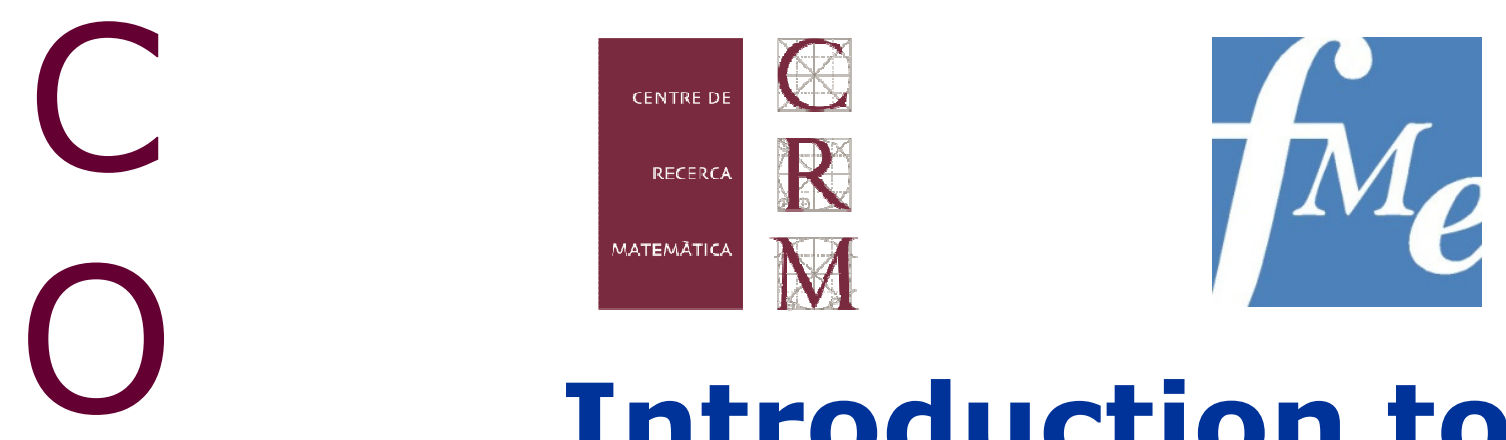

\title{
Introduction to
}

\section{Mathematical Finance}

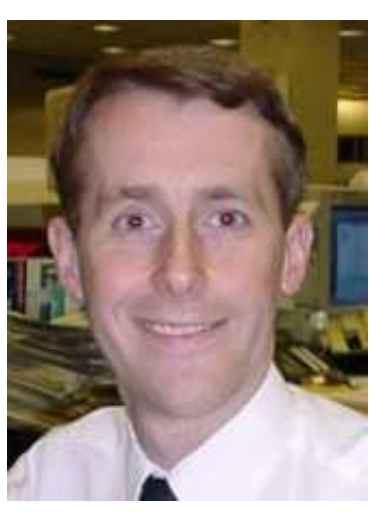

\section{Martin Baxter}

Fixed Income

Nomura International London

Martin's professional career has spanned the worlds of advanced academical research and of investment banking derivative pricing. Both of these represented in his co-authorship of the bestselling Financial Calculus, a text book on the mathematics of derivatives

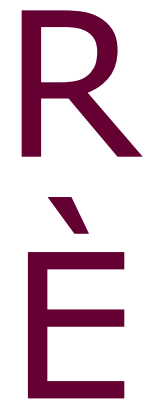

Starting with an introduction to finance and primary markets, this talk will explore the basics of derivative pricing using workable actual examples. General themes and theorems will also be developed to show how mathematics is key to modern finance.

No prior knowledge of finance or stochastics will be assumed.

\section{1 de desembre a les $12 \mathrm{~h}$,}

a la Sala d'Actes de la

Facultat de Matemàtiques i Estadística

C. Pau Gargallo, 5 - Barcelona 